\title{
Bir Devlet Hastanesinde Poliklinik Hastalarına Ait İdrar Örneklerinden İzole EdilenGenişlemiş Spektrumlu Beta-Laktamaz Pozitif Escherichia coli Suşlarının Prevalans ve Antibiyotik Duyarlılıklarının Belirlenmesi
}

\author{
Determination of the Prevalence and Antibiotic Susceptibilities of Extended \\ Spectrum Beta-Lactamase Positive Escherichia coli Strains Isolated from Urine of \\ Outpatient Patients of a State Hospital \\ Umut Safiye Şay Coşkun¹, Gökhan Coşkun² \\ ${ }^{1}$ Gaziosmanpaşa Üniversitesi Tıp Fakültesi Tıbbi Mikrobiyoloji Anabilimdalı, Tokat \\ ${ }^{2}$ Tokat Devlet Hastanesi Genel Cerrahi Kliniği, Tokat
}

\section{ÖZET}

Amaç: İdrar yolu enfeksiyonlarına yol açan mikroorganizmaların birçoğunda antibiyotiklere karşı artan oranlarda direnç geliştiği görülmektedir. Bu çalışmanın amacı Erbaa Devlet Hastanesinde, poliklinik hastalarından gönderilen idrar örneklerinden izole edilen E.coli suşlarında genişlemiş spektrumlu beta laktamaz (GSBL) oranlarının ve antimikrobiyal duyarlıık profilinin değerlendirilmesidir.

Gereç ve Yöntem: Çeşitli polikliniklerden üriner sistem enfeksiyonu şüphesiyle gönderilen orta akım idrar örneklerinden izole edilen $E$. Coli suşlarının antibiyotik duyarlılık profili ve GSBL üretimi retrospektif olarak değerlendirilmiştir. Bakteri identifikasyonu konvansiyonel yöntemlerle yapılıp suşların antibiyotik duyarlılıkları Clinical and Laboratory Standards Institute (CLSI) önerileri dikkate alınarak Kirby-Bauer disk difüzyon yöntemi ile saptanmıştır. GSBL üretimi, kombine disk yöntemi ile belirlenmiştir.

Bulgular: Toplam 516 E.coli suşu değerlendirildiğinde, GSBL üretimi 64 suşda $(\% 12,4)$ saptanmıştir. En etkili antibiyotiklerin GSBL üreten suşlarda sırasıyla imipenem, meropenem, nitrofurantoin; GSBL üretmeyen suşlarda ise imipenem, meropenem, fosfomisin, nitrofurantoin piperasilin-tazobaktam, sefoperazon-sulbaktam, olduğu belirlenmiştir. Karbapenemlere karşı direnç saptanmazken, antibiyotiklere karşı direnç durumu GSBL üretimi açısından karşılaştırıldığında, GSBL üreten E.coli suşlarında direnç

Yazışma Adresi / Correspondence:

Yrd.Doç. Dr. Umut Safiye Şay Coşkun / Kaleardı Mahallesi Muhittin Fisunoğlu Caddesi Ali Şevki EREK Yerleşkesi Tıp Fakültesi-Merkez/ TOKAT / e-mail: umutkm@hotmail.com oranlarının üretmeyen suşlara oranla daha yüksek olduğu görülmüştür ( $p<0.001)$.

Sonuç: İdrar yolu enfeksiyonlarına yol açan mikroorganizmaların birçoğunda antibiyotiklere karşı artan oranlarda direnç geliştiği görülmektedir. Her hastanenin kendi bünyesinde üreyen mikroorganizmaları ve antibiyotik duyarlılıklarını belirleyip antibiyotik bildirimlerinin bu çerçevede oluşturulması tedavinin başarısı ve direnç gelişiminin kısıtlanması adına önemlidir.

Anahtar Kelimeler: Üriner sistem enfeksiyonu, Escherichia coli, Genişlemiş Spektrumlu Beta Laktamaz, antibiyotik duyarlıı̆ı̆.

\section{ABSTRACT}

Objective: There is growing resistance in most of the microorganisms causing urinary tract infections. The aim of the present study was to evaluate the prevalence of antibiotic susceptibility of ESBL-positive E.coli strains isolated from urine samples obtained from outpatient patients in Erbaa State Hospital.

Material and Methods: Culture results retrospectively reviewed that $E$.coli isolated from mid-stream urine samples sent from various outpatient clinics with the suspicion of Urinary Tract Infections. Antibiotic susceptibility of the strains was determined using the Kirby-Bauer disc diffusion method in accordance with the principles of the Clinical and Laboratory Standards Institute (CLSI). ESBL production was studied by using the combined disc method according to CLSI standards.

Results: The prevalance of ESBL-producing strains was found as $12.4 \%$. The antibiotics to which ESBL producing 
strains are the most susceptible were as follows: imipenem, meropenem, nitrofurantoin. The antibiotics to which ESBL nonproducing strains are the most susceptible were as following: imipenem, meropenem, piperacillin-tazobactam, cefoperazone-sulbactam, fosfomycin, nitrofurantoin. Sensitivity in terms of ESBL production, resistance rates were higher in ESBL producing E.coli than in nonproducing strains $(p<0.001)$.

Conclusion: There is growing resistance in most of the microorganisms causing urinary tract infections. Every hospital should identify the antibiotic susceptibility profiles of its own prevailing strains, and their own antibiotic policies should be developed. It is importance to maintain control over increasing antibiotic resistance and treatment success.

Keywords: Urinary Infections; Escherichia coli, ESBL, antibiotic susceptibilities.

\section{Giriş}

Enfeksiyon etkenleri içerisinde ilk sıralarda gördüğümüz $E$. coli, barsak florasında yoğun olarak bulunan bir Enterobactericeae üyesidir (1). E. coli virülans faktörleri ve kullanılan antibiyotiklere geliştirdiği direnç nedeniyle üriner sistem enfeksiyonları başta olmak üzere sepsis, peritonit, yenidoğan menenjiti, yara yeri enfeksiyonuna sebep olmaktadır. Genişlemiş spektrumlu beta-laktamaz (GSBL) üretimi, Enterobactericeae üyelerinin geliştirdiği en önemli direnç mekanizmalarındandır (2). GSBL üreten bakterilerle meydana gelen enfeksiyonlar ülkemizde ve tüm dünyada mortalite ve morbiditeye neden olan önemli bir problemdir. Hastane kaynaklı enfeksiyonlarda bakterilerin GSBL üretimi ciddi bir sorun olup, toplum kökenli enfeksiyonlarda da GSBL üretimi günden güne artmaktadır $(3,4)$. Bu çalışmanın amacı hastanemizde poliklinik hastalarının idrar örneklerinden izole edilen E.coli suşlarının GSBL üretim oranlarını ve antimikrobiyal duyarlılık profilini belirleyerek hastanemizdeki antibiyotik kullanım politikalarını gözden geçirmektir.

\section{GEREÇ ve YÖNTEM}

Ocak 2011 ve Temmuz 2013 tarihleri arasında Erbaa Devlet Hastanesi Mikrobiyoloji Laboratuvarına çeşitli polikliniklerden üriner sistem enfeksiyonu şüphesi ile gönderilen 10.140 orta akım idrar örneği retrospektif olarak araştırılmıştır. İdrar örneklerinin Eosin Methylene Blue (EMB) ve \%5 koyun kanlı agarlara ekimi yapılmıştır. Ayrıca idrar örnekleri 2000 rpm 5 dakika santrifüj edilerek lökosit, epitel ve bakteri açısından değerlendirilmiştir. Kültürlerde enfeksiyon etkeni olduğu düşünülen, mililitrede tek tip $10^{4}-10^{5}$ (cfu/ml) bakteri üremesi saptanan örnekler çalışmaya alınmıştir. Bakteri identifikasyonu konvansiyonel yöntemlerle (Gram boyama, oksidaz testi, glukoz, laktoz fermentasyonu, üre testi, indol testi, sitrat, hareket özelliği vs.) belirlenen suşların antibiyotik duyarlılık testi, Clinical and Laboratory Standards Institute (CLSI) önerileri dikkate alınarak Kirby-Bauer disk difüzyon yöntemi ile yapılmıştır. GSBL üretimi, CLSI standartlarına göre kombine disk yöntemi ile araştirılmıştır (5). Standart suş olarak E.coli ATCC 25922 kullanılmıştır. Veriler SPSS 20 istatistik programı ile ki-kare testi yapılarak değerlendirilmiş olup $\mathrm{p}<$ 0,001 anlamlı olarak kabul edilmiştir.

\section{BULGULAR}

Toplam 10.140 orta akım idrar örneğinin 611'inde anlamlı $E$. coli üremesi saptanmıştır. Poliklinik hastalarından izole edilen 516 E. coli suşu çalışmaya dahil edilmiştir. E.coli suşlarının izole edildiği örneklerin gönderildiği polikliniklere göre dağılımı Tablo 1'de gösterilmiştir. 516 E.coli suşu değerlendirildiğinde, GSBL üretimi 64 suşda \%12.4 saptanmıştır. GSBL üreten ve üretmeyen tüm $E$. coli suşlarının antibiyotik duyarlılık durumu Tablo 2'de gösterilmiştir. GSBL üretmeyen suşlarda antibiyotiklere karşı en yüksek direnç sırasıyla ampisilin'e \%45.8, siprofloksasin'e \%23, trimetoprim-sulfametoksazol'e \%20.6 olarak tespit edilmiştir. GSBL üreten suşlarda ise antibiyotiklere karşı en yüksek direnç ampisilin'e $\% 100$, sefalotin'e \%100, sefuroksim'e \%100, sefotaksim'e \%100, seftazidim'e \%95.3, aztreonam'a \%95.3, siprofloksasin'e \%68.8, trimetoprimsulfametoksazol'e \%53.1, amoksisilin-klavulanik asit'e \%45.3, sefepim'e \%43.8 olarak saptanmıştir. Tüm suşların en duyarlı olduğu antibiyotikler imipenem ve meropenem olup bu antibiyotiklere karşı direnç tespit edilmemiştir. Duyarlılık sonuçları GSBL üretimi açısından karşılaştırıldığında, GSBL üreten E.coli suşlarında direnç oranlarının üretmeyen suşlara oranla daha yüksek olduğu görülmüştür.

Tablo 1. 516 E.coli izolatının polikliniklere göre dağlımı

\begin{tabular}{lcc} 
Üroloji polikliniği & 122 & 23.6 \\
Çocuk Hastalıkları plk. & 120 & 23.2 \\
Enfeksiyon Hastalıkları plk. & 92 & 17.8 \\
Genel Cerrahi polikliniği & 73 & 14.1 \\
Dahiliye polikliniği & 59 & 11.4 \\
Kadın Doğum polikliniği & 37 & 7.1 \\
Acil polikliniği & 13 & 2.5 \\
\hline
\end{tabular}

Toplam 516 100 
Idrar Kültürü, Escherichia coli, Genişlemiş Spektrumlu Beta Laktamaz, Antibiyotik Duyarlıı̆̆ı Urine Culture, Escherichia coli, Extended Spectrum Beta-Lactamase, Antibiotic Susceptibility

Tablo 2. GSBL pozitif ve negatif $E$. coli suşlarının antibiyotik direnç durumları

\begin{tabular}{|c|c|c|c|c|c|}
\hline & & Dirençli & Duyarlı & $x 2$ & p-değeri \\
\hline \multirow{2}{*}{ Ampisilin } & GSBL (+) & 64 & 0 & \multirow{2}{*}{66,052} & \multirow{2}{*}{$<0,001$} \\
\hline & GSBL (-) & 207 & 245 & & \\
\hline \multirow{2}{*}{ AMC } & GSBL (+) & 27 & 37 & \multirow{2}{*}{156,35} & \multirow{2}{*}{$<0,001$} \\
\hline & GSBL (-) & 6 & 446 & & \\
\hline \multirow{2}{*}{ Gentamisin } & GSBL (+) & 14 & 50 & \multirow{2}{*}{27,736} & \multirow{2}{*}{$<0,001$} \\
\hline & GSBL (-) & 20 & 432 & & \\
\hline \multirow{2}{*}{ Sefalotin } & GSBL (+) & 64 & 0 & \multirow{2}{*}{206,197} & \multirow{2}{*}{$<0,001$} \\
\hline & GSBL (-) & 71 & 381 & & \\
\hline \multirow{2}{*}{ Sefuroksim } & GSBL (+) & 64 & 0 & \multirow{2}{*}{381,154} & \multirow{2}{*}{$<0,001$} \\
\hline & GSBL (-) & 19 & 433 & & \\
\hline \multirow{2}{*}{ Sefoksitin } & GSBL (+) & 0 & 64 & \multirow{2}{*}{1,888} & \multirow{2}{*}{0,169} \\
\hline & GSBL (-) & 13 & 439 & & \\
\hline \multirow{2}{*}{ Sefotaksim } & GSBL (+) & 64 & 0 & \multirow{2}{*}{398,188} & \multirow{2}{*}{$<0,001$} \\
\hline & GSBL (-) & 16 & 436 & & \\
\hline \multirow{2}{*}{ Seftazidim } & GSBL (+) & 61 & 5 & \multirow{2}{*}{446,038} & \multirow{2}{*}{$<0,001$} \\
\hline & GSBL (-) & 5 & 447 & & \\
\hline \multirow{2}{*}{ Aztreonam } & GSBL (+) & 61 & 3 & \multirow{2}{*}{462,253} & \multirow{2}{*}{$<0,001$} \\
\hline & GSBL (-) & 3 & 449 & & \\
\hline Sefenim & GSBL (+) & 28 & 3 & 184307 & $<0001$ \\
\hline כетеріп & GSBL (-) & 3 & 449 & 104,307 & $<, 001$ \\
\hline CES & GSBL (+) & 5 & 59 & 156609 & $=0001$ \\
\hline CES & GSBL (-) & 4 & 448 & 13,0099 & $<0,001$ \\
\hline TZP & GSBL (+) & 4 & 60 & 13074 & $<0001$ \\
\hline $12 C r$ & GSBL (-) & 3 & 449 & $10,0 / 4$ & $<, 001$ \\
\hline Iminenem & GSBL (+) & 0 & 64 & & \\
\hline immenem & GSBL (-) & 0 & 452 & & \\
\hline Meronenem & GSBL (+) & 0 & 64 & & \\
\hline & GSBL (-) & 0 & 452 & & \\
\hline SYT & GSBL (+) & 34 & 30 & 32012 & $<0001$ \\
\hline JAI & GSBL (-) & 93 & 359 & $52, U \perp 2$ & $\langle 0,001$ \\
\hline Encomicin & GSBL (+) & 6 & 58 & 25104 & $<0001$ \\
\hline rosiomisin & GSBL (-) & 1 & 451 & 35,104 & $<0,001$ \\
\hline Nitrofurantoin & GSBL (+) & 3 & 61 & 10.528 & $<0001$ \\
\hline & GSBL (-) & 2 & 450 & & \\
\hline Sinroflokcasin & GSBL (+) & 44 & 20 & 57342 & $<0001$ \\
\hline SIPTOIIOKSdSIII & GSBL (-) & 104 & 348 & (31, & $\angle 0,001$ \\
\hline Iovflocacin & GSBL (+) & 28 & 36 & 11,126 & $=0001$ \\
\hline Levorioksasin & GSBL (-) & 55 & 397 & $41,4<0$ & $<0,001$ \\
\hline
\end{tabular}

AMC* Amoksisilin-klavulonik asit

CES** Sefoperazon-sulbaktam

TZP*** Piperasilin-tazobaktam

SXT**** Trimetoprim-sülfametoksazol 


\section{TARTIŞMA}

Üriner sistem enfeksiyonları tüm bakteriyel enfeksiyonlar içerisinde en sık görülen enfeksiyon olup en fazla izole edilen etken $E$. coli'dir. Antibiyotiklerin kontrolsüz kullanımı, bakterilerin direnç mekanizmaları geliştirmelerine neden olmaktadır. Artan direnç tedavisi giderek güçleşen, maliyeti artan enfeksiyonlara yol açmaktadır. GSBL üretimi $E$. coli'nin en önemli direnç mekanizması olup özellikle hastane kaynaklı enfeksiyon olmak üzere toplum kökenli suşlarda da giderek artan oranlarda karşımıza çıkmaktadır $(3,4)$.

Çoğunlukla plazmidlerce kodlanan GSBL enzimleri beta-laktam antibiyotiklerdeki beta-laktam halkasının amid bağlarını parçalayarak sefotaksim, seftriakson, seftazidim gibi oksi-imino sefalosporinler ile aztreonam gibi monobaktamlara karşı direnç gelişimine neden olmaktadır. Ancak bu enzimlerin sfoksitin gibi sefamisin grubu sefalosporinlere karşı etksi yoktur. Bu enzimler başta $E$. coli ve Klebsiella türleri olmak üzere Citrobacter, Serratia ve Salmonella gibi diğer Enterobacteriaceae üyelerinde ve bazı nonfermentatif bakterilerde de bulunabilmektedir $(6,7)$.

GSBL üretmeyen $E$. coli suşlarıyla yapılan çalışmalarda Aydemir ve ark. (18) sefuroksim, seftazidim, sefotaksime karşı sırayla \%37, \%32, \%37, Duman ve ark. (11) çalışmalarında sefalotin, sefuroksim, seftazidim, sefotaksim, aztreonam, sefepime karşı sırasıyla \%69.3, \%48.5, \%36.8, \%37, \%38.5, \%36.7 direnç tespit etmişlerdir. Uğur ve ark. (12) yine ayaktan tedavi alan hastalarda sefalotin ve sefuroksim direncini sırasıyla $\% 45, \% 13$ bulurken seftazidim, sefotaksim, sefepime karşı direnç saptamamışlardır. Bu çalışmada ise sefalotin, sefuroksim, sefotaksim, sefoxitin, seftazidim, aztreonam, sefepime karşı direnç sırasıyla \%15.7, \%4.2, \%3.5, \%2.9, \%1.1, \%0.7, \%7 tespit edilmiştir. Toplum kaynaklı üriner sistem enfeksiyonlarının tedavisinde ikinci ve üçüncü kuşak sefalosporinler sıklıkla kullanılan antibiyotiklerdir (20). GSBL üretmeyen suşlarda direnç oranları, bu çalışmada diğer çalışmalara göre daha düşük tespit edilmiştir. Bunun sebebinin hastanemizde sefalosporinlerin üriner sistem enfeksiyonlarında ampirik tedavide ilk tercih olarak kullanılmamasına bağlı olduğu düşünülmektedir.

GSBL üretiminin yıllara göre giderek artmakta olduğu gözlenmektedir $(9,10)$. Ülkemizde ayaktan tedavi gören poliklinik hastalarından izole edilen $E$. coli suşlarında GSBL oranları \%13 ile \%26 arasında tespit edilmiştir (11-17). Bu çalışmada 516 E. coli suşunun GSBL üretimi 64/516 (\%12,4) olarak saptanmıştır. Çalışmalar karşılaştırıldığında bu çalışmanın diğer çalışmalar ile uyumlu olduğu görülmektedir.
EARS-NET'in 2012 yılında açıkladığı verilere göre Avrupa'da 28 ülkeden 74.687 E. coli izolat rapor edilmiştir. Bu izolatların \%39.5'i tüm antibiyotik gruplarına duyarlı saptanmıştır. Avrupa'da 3. kuşak sefalosporinlere karşı direncin \%4.4 oranı ile en düşük tespit edildiği ülke ile İsveç, en yüksek direnç ise \%38.1 oranı ile Bulgaristan'dan bildirilmiştir. Aynı raporda Avrupa'dan bildirilen aminoglikozidlere karşı en düşük direnç \%3.6 ile İzlanda, en yüksek direnç \%26.5 ile Bulgaristan'dan tespit edilmiştir. Kinolonlara karşı direncin en düşük saptandığı ülke İzlanda olup \%9.7 oranında direnç tespit edilirken en yüksek direnç oranları \%42 ile Kıbrıs ve İtalya'dan bildirilmiştir. Karbapenemlere karşı direnç \%0.1 olarak açıklanmıştır (8).

Ülkemizde yapılan çalışmalarda Ampisiline karşı gelişen direnç oranlarını Duman ve ark. (11) \%77.3, Uğur ve ark.(12) ise \%60 olarak tespit etmişlerdir. Bu çalışmada GSBL üretmeyen E.coli suşlarında en yüksek direnç oran ı \%45.8 ile ampisiline karşı saptanmıştır. Tüm çalışmalar değerlendirildiğinde ampisiline karşı yüksek oranda direnç tespit edilmiştir. Başta üst solunum yolu enfeksiyonları olmak üzere ampirik tedavide çok sık kullanılması ampisiline karşı direnç gelişimine neden olmuştur. Ampisilinin üriner sistem enfeksiyonlarında ampirik tedavide tercih edilmemesi gerektiği düşünülmektedir.

Amoksisilin-klavulanik asit ile yapılan çalışmalarda direnç oranları \%37.48 ile \%56.3 arasında saptanmıştır $(14,15,16)$. Bu çalışmada ise GSBL üreten ve üretmeyen suşlarda sırasıyla \%45.3 ve \%13 tespit edilmiş olup diğer çalışmalarla uyumlu olduğu görülmüştür.

Ülkemizde yapılan çalışmalarda gentamisine karşı direnç oranlarını Aydemir ve ark. (18) GSBL üretmeyen suşlarda \%29.1, GSBL üretenlerde \%62.2, Gülcan ve ark. (19) GSBL üreten suşlarda \%9.4, GSBL üretmeyenlerde \%46.8 tespit etmişlerdir. Uğur ve ark. (12) çalışmalarında ise GSBL üretmeyen suşlarda \%9, GSBL üretenlerde \%49 bildirilmiştir. Bu çalışmada GSBL üretmeyen suşlarda \%4.4, GSBL üreten suşlarda ise \%21.9 saptanmış olup sonuçlar literatürle uyumludur. Gentamisin direnci düşük olduğundan $E$. coli'nin neden olduğu üriner sistem enfeksiyonlarında tercih edilebilmektedir.

Duman ve ark. (11) çalışmalarında ayaktan tedavi alan hastalarda piperasilin-tazobaktam ve sefoperazonsulbaktama karşı direnç oranları sırasıyla \%18.5, \%13.3 (11) saptanırken Uğur ve ark.(12) çalışmalarında piperasillin-tazobaktama \%21 olarak tespit edilmiştir. Bu çalışmada piperasillin-tazobaktam ve sefoperazonsulbaktama karşı direnç sırasıyla GSBL üretmeyen 
suşlarda \%0.7, \%0.9, GSBL üreten suşlarda \%6.3, \%7.8 saptanmıştır. Diğer çalışmalara göre direnç oranının daha düşük olması, hastanemizde üriner sistem enfeksiyonlarında bu antibiyotiklerin sık kullanılmamasından kaynaklanmaktadır.

Ülkemizden bildirilen çalışmalarda karbapenemlere karşı tespit edilen direnç oranlarını Ardıç ve ark. (21) imipeneme karşı 2005-2007 yıllarında sırasıyla \%3.1, \%21, \%1.6 saptamışlardır. Uğur ve ark.(12) meropeneme karşı GSBL üreten suşlarda $\% 5$ oranında direnç saptarken GSBL üretmeyen suşlarda direnç tespit etmemişlerdir. Aydemir ve ark. (18) ve Duman ve ark. (11)'nın çalışmalarında ise imipenem ve meropeneme karşı direnç tespit edilmemiştir. Bu çalışmada da direnç tespit edilmemiş olup, nedeninin uygulanan antibiyotik kısıtlı bildirim politikalarına bağı olarak kullanımının sınırlandırıması olduğu düşünülmektedir.

Trimetoprim-sülfametoksazol ile yapılan çalışmalara baktığımızda Aydemir ve ark.(18) 2004-2005'deki çalışmalarında \%46.7 oranında, Duman ve ark. (11) çalışmalarında ise ayaktan tedavi gören hastalarda \%57.5 oranında direnç bildirmişlerdir. Gülcan ve ark .(19) çalışmalarında GSBL üretmeyen suşlarda \%37.2, GSBL üreten suşlarda \%75.3 direnç tespit edilmiştir. Bu çalışmada direnç oranı GSBL üretmeyen suşlarda \%20 .6, GSBL üreten suşlarda \%53.1 olup diğer çalışmalarda da olduğu gibi trimetoprim-sülfametoksazol en dirençli antibiyotikler arasında bulunmaktadır.

Fosfomisin idrarda yüksek konsantrasyonda bulunabilmesi, diğer antibiyotiklerle çapraz direnç oranlarının düşük olması nedeniyle komplike olmayan üriner sistem infeksiyonlarının tedavisinde ilk tercih edilen antibiyotiklerdendir (22). Arman ve ark (14) fosfomisine karşı direnci \%0.9 olarak tespit ederken, Mengeloğlu'nun (16) çalışmasında GSBL üreten ve üretmeyen suşlarda direnç saptanmamıştr. Bu çalışmada GSBL üreten ve üretmeyen suşlarda sırasıyla \%9.4 ve \%0.2 oranında direnç tespit edilmiştir. Fosfomisin ampirik tedavide ilk seçilecek antibiyotiklerdendir.

Üriner sistem enfeksiyonlarında ampirik tedavide en sık kullanılan antibiyotiklerden biri olan nitrofurantoin ile ilgili çalışmalarda Gülcan ve ark. (19) GSBL üretmeyen suşlarda \%16.9, GSBL üretenlerde \%27.1 (19), Uğur ve ark. (12) ayaktan tedavi alan hastalarda GSBL üretmeyen suşlarda \%6, GSBL üreten suşlarda \%19 direnç saptamışlardır. Bu çalışmada ise GSBL üretmeyen suşlarda $\% 0.4$, üreten suşlarda $\% 4.7$ direnç tespit edilmiştir. Nitrofurantoin direnç oranları diğer çalışmalarda olduğu gibi bizim çalışmamızda da düşük olup üriner sistem enfeksiyonları için nitrofurantoin en etkili antibiyotikler arasındadır.

Ülkemizde yapılan çalışmalarda E.coli suşlarında siprofloksasin ve levofloksasine karşı direnç oranları şu şekildedir: Siprofloksasine karşı direnç Aydemir ve ark. (18) \%34.3 oranında, Duman ve ark. (11) \%41.4 oranında saptamışlardır. Gülcan ve ark. (19) çalışmalarında idrar örneklerinden üreyen GSBL üretmeyen suşlarda levofloksasine karşı direnç \%20 .7, GSBL üretenlerde ise \%77.7 bulunmuştur (19). Uğur ve ark. (12) çalışmalarında ise GSBL üretmeyen suşlarda siprofloksasin ve levofloksasine karşı direnç sırasıyla \%31, \%24, GSBL üreten suşlarda ise \%71, $\% 75$ olarak tespit edilmiştir. Bu çalışmada GSBL üretmeyen $E$. coli suşlarında direnç oranları sırasıyla $\% 23, \% 12$, GSBL üreten suşlarda ise $\% 68.8, \% 43.8$ saptanmıştır. Direnç oranlarımızın çalışmalarla uyumlu olduğu görülmüştür. Kinolonlar geniş spektrumlu antibiyotikler olup başta üriner sistem enfeksiyonları olmak üzere birçok enfeksiyonda ampirik tedavide yaygın kullanılmasından dolayı direncin yıllar içinde artth̆ı düşünülmektedir (23). Artan direnç ve kinolon grubu ilaçlar içerisinde çapraz direnç gelişme riski kinolonların kullanımını sınırlandırmaktadır (24).

Sonuç olarak bu çalışmada GSBL üreten E.coli suşlarının direnç oranlarının üretmeyenlere göre daha yüksek olduğu görülmüştür. Ampisilin, amoksisilinklavulanik asit, thrimethoprim-sulfametaksazol ve kinolonlara karşı direnç yüksek bulunmuştur. Bu antibiyotiklerin ampirik tedavide tercih edilmemesi gerekmektedir. Ulusal politikaların yanı sıra, her hastane kendi antibiyotik duyarlılıklarını belirleyip antibiyotik bildirimlerini bu çerçevede oluşturmalıdır. $\mathrm{Bu}$ çalışmaların; tedavinin başarısı, maliyetin düşürülmesi ve direnç gelişiminin kısıtlanması adına önemli olduğunu düşünülmektedir.

\section{KAYNAKLAR}

1. Winn, W, Jr, S. Allen, W. Janda, E. Koneman, G. Procop, P. Schreckenberger, and G. Woods. Koneman's color atlas and textbook of diagnostic microbiology, 6th edition. Lippincott Williams \& Wilkins, Baltimore, MD. 2006

2. Yetkin G, Kuzucu Ç, Çalışkan A, Ay S. Kan kültürlerinde üreyen Escherichia coli'lerin antibiyotik duyarlılıkları, GSBL oranları ve hastane birimlerine göre dağılımı. İnönü Üniversitesi Tıp Fakültesi Derg. 2006;13(3):14750. 
3. Oteo J, Lázaro E, de Abajo FJ, Baquero F, Campos J. Antimicrobial-resistant invasive Escherichia coli, Spain. Emerg Infect Disesae 2005;11(4):546-53.

4. Ruppé $E$, Hem S, Lath $S$ et al. CTX-M b-lactamases in Escherichia coli from community-acquired urinary tract infections Cambodia. Emerg Infect Dis. 2009;15(5):7418.

5. Clinical and Laboratory Standards Institute. Performance Standards for Antimicrobial Susceptibility Testing; Twenty-first informational supplement, CLSI document M100-S21, CLSI, Wayne (2011).

6. Gür D. Beta-laktamazların sınıflandırılması. FloraInfeksiyon Hast Klinik Mikrobiyoloji Derg. 1996;1(2):806.

7. Azavedo PA, Gonçalves ALS, Musskopf MI, Ramos CG, Dias CA. Laboratory tests in the detection of extended spectrum beta-lactamase production: National Committee for Clinical Laboratory Standards (NCCLS) screening test, the E-Test, the double disk confirmatory test, and cefoxitin susteptibility testing. Brazil J Infect Dis. 2004;8:372-7.

8. Surveillance Report. Antimicrobial resistance surveillance in Europa 2012 www.ecdc.europa.eu

9. Albayrak N, Kaya Ş. Çeşitli klinik örneklerden izole edilen Escherichia coli ve Klebsiella pneumoniae suşlarının genişlemiş spektrumlu beta laktamaz üretimleri ve antibiyotik direnç oranları. Türk Mikrobiyol Cem Derg. 2009;39:16-21.

10. Akyar I, Kocagöz S, ve ark. Beş yılda izole edilen 15434 Escherıchıa coli ve 3178 Klebsıella spp. suşunda genişlemiş spektrumlu beta-laktamaz üretiminin yıllara, kliniklere ve örnek türlerine dağılımı. ANKEM Derg. 2010; 24(1):34-41.

11. Duman Y, Güçlüer N, Serindağ A, Tekerekoğlu M.S. Escherichia coli suşlarında antimikrobiyal duyarlılık ve genişlemiş spektrumlu Beta laktamaz (GSBL) varlığı. Firat Tıp Derg. 2010; 15(4):197-200.

12. Uğur A R, Türk Dağı H, Tuncer İ, Fındık D, Arslan U. İdrar kültürlerinden izole edilen Esherıchıa coli suşlarının antibiyotik duyarlılığı ve genişlemiş spektrumlu Betalaktamaz oranı. Ankem Derg. 2013; 27(1):13-8.

13. Gözüküçük R., Çakıroğlu B., Nas Y. Toplum kaynaklı üriner sistem enfeksiyonu etkeni olarak saptanan Escherichia coli izolatlarının antibiyotik duyarlılıkları. JAREM 2012; 2:101-3.
14. Arman D, Ağalar C, Dizbay $M$ ve ark. Birinci basamak sağlık merkezlerinde toplum kökenli alt üriner sistem enfeksiyonları: etkenler ve antimikrobiyal duyarlılıkları Mediterr J Infect Microb Antimicrob. 2012;1:10 http:// www.mjima.org

15. Aykan Ş B, Çiftci i $H$. Türkiye'de idrar kültürlerinden izole edilen Escherichia coli suşlarının antibiyotiklere direnç durumu: bir meta-analiz. Mikrobiyol Bul 2013; 47(4): 603-18.

16. Mengeloğlu F Z, Demircan F, Oduncu M K. İdrar kültürlerinden soyutlanan Escherıchı coli izolatlarının fosfomisine karşı in-vitro duyarlılıklarının değerlendirilmesi. ANKEM Derg. 2011;25(2):99-102

17. Deveci Ö, Yula $E$, Tekin A. İdrar kültürlerinden izole edilen Escherichia coli suşlarında beta-laktamaz sıklığı ve antibiyotik direnci. Klin Den Ar Derg. 2010; 1(3):18286.

18. Aydemir H, Yalçın A, Pişkin N, Gürbüz $Y$, Türkyılmaz R. Escherichia coli ve Klebsiella pneumoniae suşlarının genişlemiş spektrumlu B-laktamaz üretme ve antibiyotik direnç oranları. Klimik Derg. 2006;19(2):638.

19. Gülcan A, Aslantürk A, Gülcan E. İdrar kültürlerinden izole edilen mikroorganizmalar ve in vitro antibiyotik duyarlılık durumları. Abant Med J 2012;1(3):129-35.

20. Topçu AW, Söyletir G, Doğanay M. Enfeksiyon hastalıkları ve mikrobiyolojisi 3.Baskı, Nobel Tıp Kitabevleri 2008. Cilt 1, p.1487-8.

21. Ardıç $\mathrm{N}$, Karakaş A.Yatan hastalardan izole edilen $E$. coli ve $K$. Pneumoniae suşlarının çeşitli antibiyotiklere direnç durumu: beş yıllık veriler. Türk Fiz Tıp Rehabilitasyon Derg. 2012;58(3):189-93.

22. Falagas ME, Giannapoulou KP, Kokolakis GN, Rafailidis PI. Fosfomycin: Use beyond uninary tract and gastrointestinal infections, Clin Infect Dis. 2008;46(7):1069-77.

23. Yılmaz F. F., Ermertcan Ş. İdrar yolu infeksiyonlarından izole edilen Escherıchı Coli kökenlerinde florokinolon direncinin araştırılması. Infeksiyon Derg. 2005;19(4):429-33.

24. Gales AC, Jones RN, Gordon KA, et al. Activity and spectrum of 22 antimicrobial agents tested against urinary tract infection pathogens in hospitalized patients in Latin America: Report from the second year of the SENTRY Antimicrobial Surveillance Program (1998). J Antimicrob Chemother. 2000;45:295-303. 